\title{
Interpersonal and inter-organisational relationships in supply chain integration: An exploration of third-party logistics providers in South Africa
}

\begin{tabular}{|c|c|}
\hline \multicolumn{2}{|c|}{$\begin{array}{l}\text { Authors: } \\
\text { Tiaan van Staden }{ }^{1} \text { (D) } \\
\text { Wesley Niemann }{ }^{1} \text { (D) } \\
\text { Arno Meyer }{ }^{1} \text { (D) }\end{array}$} \\
\hline \multicolumn{2}{|c|}{$\begin{array}{l}\text { Affiliations: } \\
{ }^{1} \text { Department of Business } \\
\text { Management, Faculty of } \\
\text { Economic and Management } \\
\text { Sciences, University of } \\
\text { Pretoria, Pretoria, } \\
\text { South Africa }\end{array}$} \\
\hline \multicolumn{2}{|c|}{$\begin{array}{l}\text { Corresponding author: } \\
\text { Wesley Niemann, } \\
\text { wesley.niemann@up.ac.za }\end{array}$} \\
\hline \multicolumn{2}{|c|}{$\begin{array}{l}\text { Dates: } \\
\text { Received: } 04 \text { May } 2020 \\
\text { Accepted: } 04 \text { Aug. } 2020 \\
\text { Published: } 23 \text { Oct. } 2020\end{array}$} \\
\hline \multicolumn{2}{|c|}{$\begin{array}{l}\text { How to cite this article: } \\
\text { Van Staden, T., Niemann, W. } \\
\text { \& Meyer, A., 2020, } \\
\text { 'Interpersonal and inter- } \\
\text { organisational relationships } \\
\text { in supply chain integration: } \\
\text { An exploration of third-party } \\
\text { logistics providers in South } \\
\text { Africa', Acta Commercii } \\
20(1), \text { a867. https://doi. } \\
\text { org/10.4102/ac.v20i1.867 }\end{array}$} \\
\hline \multicolumn{2}{|c|}{$\begin{array}{l}\text { Copyright: } \\
\text { (C) 2020. The Authors } \\
\text { Licensee: AOSIS. This } \\
\text { is licensed under the } \\
\text { Creative Commons } \\
\text { Attribution License. }\end{array}$} \\
\hline \multicolumn{2}{|l|}{ Read online: } \\
\hline 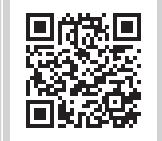 & $\begin{array}{l}\text { Scan this QR } \\
\text { code with your } \\
\text { smart phone or } \\
\text { mobile device } \\
\text { to read online. }\end{array}$ \\
\hline
\end{tabular}

Orientation: Third-party logistics (3PL) providers act as integrators between suppliers, manufacturers and retailers whilst providing product movement and logistics information flow throughout the supply chain. Firms have been integrating their supply chains and strengthening relationships with 3PLs to enhance supply chain performance, achieve cost reduction, improve service and shorten lead times. However, the innate association between interpersonal relationships (IPRs) and supply chain integration (SCI) has received little attention in literature.

Research purpose: To investigate the role of IPRs on inter-organisational relationships (IORs) during both the formative and the operational stages of SCI.

Motivation for the study: Although SCI has received increased attention over the past few years, significant gaps related to IPRs and SCI in the service sector still exist in the literature.

Research design, approach and method: This study was conducted in the South African 3PL industry. A generic qualitative research design was used to collect data from 12 middle- to senior-level managers employed by 3PL organisations in South Africa. This study used a thematic analysis approach to analyse the collected data.

Main findings: This study found that IPRs played a significant role in IORs during the SCI process, such as the improved ease of doing business, enhanced trust, enhanced business accommodation and improved customer retention. However, the negative influences of IPRs should not be ignored, such as unethical practices, crossing the line, bias judgement and personal issues affecting the business. Furthermore, this study identified how IPR elements, namely personal affection, credibility and communication mature throughout the SCI process. The findings indicated that the role of personal affection matures and plays a more significant role during the operational stages of SCI, whereas personal credibility and communication had shown to play a significant role during both the formative and the operational stages of SCI.

Practical/managerial implications: This study provided managerial insights into the role of IPRs and the importance of leveraging personal affection, credibility and communication to influence IORs during the SCI process.

Contribution/value-add: This study contributes to the existing body of knowledge by being the first empirical study to investigate the role of IPRs on IORs during different stages of SCI in the South African 3PL context. This study reveals contradicting results in the evolutionary directions of personal affection, credibility and communication in their influence on IOR during the SCI process compared to the findings by Wang et al. (2018a:1170-1186).

Keywords: supply chain integration; interpersonal relationships; inter-organisational relationships; third-party logistics; generic qualitative research; semi-structured interviews; South Africa.

\section{Introduction}

Reid Hoffman, co-founder of LinkedIn, was quoted saying, 'No matter how brilliant your mind or strategy, if you are playing a solo game, you will always lose out to a team'. Increased competition, globalisation, commoditisation, uncertainty, complexity and demanding customers have changed the business landscape by increasing the importance of product availability (Christopher 2016:15). As a result, firms are driven to act as integrated entities (Vermeulen, Niemann \& Kotzé 2016:2). Through integration, firms can increase the reliability of delivery and improve responsiveness to the changing business landscape (Danese, Romano \& Formentini 2013:126). Concomitantly, Porter 
(2019:49) stated that supply chain integration (SCI) initially started with a system perspective that an integrated process is better than segregated functions. Third-party logistics (3PL) allow supply chain partners to integrate their supply chains, which lead to enhanced efficiency (Rood et al. 2018:3). 3PL also has the potential to improve overall supply chain performance by reducing costs and shortening lead times simultaneously (Zhang \& Okoroafo 2015:38). As a result, SCI between firms and 3PLs may lead to a competitive advantage (Marchet et al. 2018:139-161).

Supply chain integration is an essential strategy for improved performance and success in firms and their respective supply chains (Cao et al. 2015:24; Huo 2012:596; Zhang \& Huo 2013:544). By incorporating SCI, the supply chain partners can share more information, from strategic alliances and integrate processes. This allows supply chain partners to reduce the bullwhip effect, costs and solve inventory problems (Yunus \& Tadisina 2016:91). Many firms are integrating and collaborating with 3PLs to increase capabilities, efficiencies and competencies in the supply chain, resulting in a competitive advantage (Huo, Ye \& Zhao 2015:161).

This has resulted in relationships between firms and 3PL providers to be strategic rather than transactional (Niemann et al. 2018:1749). To capture the full advantage of outsourcing logistics activities, firms are required to have strong relationships with 3PLs (Gunasekaran et al. 2015:162). Interpersonal relationships (IPRs) and inter-organisational relationships (IORs) have therefore been identified in the literature as influencers of SCI (Wang et al. 2016:839, 2018a:1170-1171, 2018b:829-839).

Interpersonal relationships are the relationships between individuals who are involved in supply chain activities (Wang et al. 2016:839). IPRs enhance SCI by developing and maintaining supply chain relationships at the inter-organisational level (Wang et al. 2016:839). IORs relate to the relationships between two or more different firms working together towards mutual goals (Ebers 2015:621-625). IPRs initiate the formation of IORs through the personal relationships created between supply chain partners (Wang et al. 2018a:1178). This is evident as IORs emerge from social bonds between individuals, given that boundary spanners (job positions where individual employees are required to have direct contact with the employees of other firms) work closely with the individuals from other firms (Barnes et al. 2015:10).

As SCI develops, the role of IPRs on IORs evolves (Wang et al. 2018a:1185). IPRs have a less significant role in the operational stage compared to the formative stage of SCI (Wang et al. 2018a:1179). The formative stage refers to the stage in SCI, where strategic alliances, information integration and process integration are still developing and not completely formed. The operational stage, in contrast, refers to the stage where strategic alliances, information integration and process integration are fully developed, and supply chain partners are interdependent of each other. During the operational stage of SCI, formal IORs between firms play a more significant role than IPRs, because it is the firm they do business with that controls the resources (Wang et al. 2018a:1184).

Previous research has examined IOR factors from an organisational level, but limited research has been conducted on the role of IPRs in SCI (Gligor \& Holcomb 2013:329; Wang et al. 2018a:1171). Although SCI has received increased attention over the past few years, literature focused more on the comparisons and conceptual definitions of SCI in the manufacturing sector with limited focus on service supply chain integration (SSCI) (Aitken et al. 2016:188; Boon-itt, Wong \& Wong 2017:1; Wang et al. 2018b:829). Therefore, significant gaps related to IPRs and SCI in the service sector still exist in the literature. Services require close person-to-person contact between individual staff members of firms, and because of the lack of research pertaining to this relationship, further investigation is needed (Shaiq et al. 2020:245). The role of IPRs on IORs during the formative and operational stages of SCI has received minimal attention in literature, especially in developing countries (Wang et al. 2018a:1171; Yunus \& Tadisina 2016:90).

Different results could be expected, as theories established in developed countries often do not apply to the practices and scenarios of developing countries as developing countries have different growth patterns and business developments (Yunus \& Tadisina 2016:90). Goldsby and Autry (2011:324) support the execution of supply chain management studies that reproduce findings across contexts. The purpose of this generic qualitative study was to replicate the previous research by Wang et al. (2018a:1170-1186), in a South African service sector. This study will, therefore, be able to determine the transferability of the findings. More specifically, this study investigated the role of IPRs on IORs during both the formative and the operational stages of SCI by conducting semi-structured interviews with 3PLs.

This study aimed to answer the following research questions:

- How do IPRs amongst boundary spanners influence the occurrence of IORs in the South African 3PL industry?

- What is the role of IPRs on IORs during the formative stage of SCI in the South African 3PL industry?

- How does the role of IPRs amongst boundary spanners on IORs change during the operational stage of SCI in the South African 3PL industry?

This study contributes to the existing body of knowledge by being the first empirical study to investigate the role of IPRs on IORs during different stages of SCI in the South African 3PL context. This study also equips supply chain managers and 3PL providers to understand the role of IPRs on IORs during various stages of SCI. As a result, supply chain managers and 3PL providers can gain an 
understanding of the influences of IPRs on IORs during SCI practices. Finally, this study reveals contradicting results in the evolutionary directions of personal affection, credibility and communication in their influence on IOR during the SCI process compared to the findings by Wang et al. (2018a:1170-1186).

\section{Literature review}

This section provides an overview of the relevant literature pertaining to 3PL, SCI, IPRs, IORs and the role of IPRs during different stages of SCI.

\section{Third-party logistics providers}

Third-party logistics providers are service firms who perform and manage a range of logistics services such as distribution, warehousing, transportation and other value-adding services such as repacking and breaking bulk for their clients (Christopher 2016:249). South African firms are driven to outsource and integrate with 3PL providers to conform to the global standards of improving customer service, focus on core competencies, reduce costs and cover expanded geographic markets (Luke \& Waugh 2011:354). Clients can gain various benefits from outsourcing logistics activities to a 3PL, which include cost reductions, improvements in service and remaining focused on core competencies (Leuschner et al. 2014:21; Zhang \& Okoroafo 2015:38). These benefits drive many firms to seek integration opportunities with 3PL providers.

\section{Supply chain integration}

Supply chain integration is a multi-dimensional concept defined as the degree firms coordinate and collaborate with supply chain partners to align strategies, resources, information, knowledge and processes effectively and efficiently to meet customer's needs (Cao et al. 2015:26; Liu et al. 2016:14; Stevens \& Johnson 2016:22). Supply chain integration includes internal integration and external integration (Huo 2012:597; Stevens \& Johnson 2016:22). Internal integration refers to the intra-organisational integration of departmental functions to improve and gain competitive advantage (Vermeulen et al. 2016:2). External integration refers to a firm collaborating with its supply chain members such as suppliers and customers to fulfil their needs (Zhang \& Huo 2013:547). The focus of this study is on external integration, as this study focuses on IPRs and IORs between firms. Supply chain integration allows organisations to realise many benefits through collaboration with supply chain partners (Lo et al. 2018:524; Yunus \& Tadisina 2016:91), which include reduced inventory, operating costs, transactional costs and improved information sharing, customer service, financial performance and supply chain performance (Yunus \& Tadisina 2016:91; Zhang \& Huo 2013:544). By surpassing firm boundaries, SCI enables firms to form strategic alliances, share information and coordinate operational processes (Wang et al. 2018a:1173).

\section{Strategic alliance as an element of supply chain integration}

Strategic alliance refers to long-term relationships between supply chain partners to achieve mutual strategic goals, with joint decision making and synchronised planning (Liu et al. 2016:15; Wang et al. 2018b:830). Strategic alliances provide multiple benefits through joint production, processes and scheduling (Zhang \& Huo 2013:550), which include crossbusiness synergies, improved costs, technology, new market access, flexibility, scale economics, geographic reach, competence development, quality and delivery (Haq \& Boddu 2017:10; Išoraite 2014:42). Strategic alliances also improve supply chain performance in multiple core areas including inventory, sales, customer service, information and forecasts (Haq \& Boddu 2017:10). Strategic alliances are based on sharing resources, information, knowledge, risks and joint decision making to achieve common goals (Wang et al. 2016:845).

\section{Information integration as an element of supply chain integration}

Information integration is the coordination of information transfer, collaborative communication and supporting technology among firms in supply chains' (Leuschner, Rogers \& Charvet 2013:38). Information integration includes information sharing between supply chain partners about several supply chain activities, such as information about delivery schedules, production, inventory and sales (Liu et al. 2016:15). Information integration has shown to provide multiple benefits. Firstly, supply chain partners can reduce the effects of the bullwhip effect (Yunus \& Tadisina 2016:91). Secondly, information integration assists in the alignment of strategic, operational and tactical decisions between supply chain partners (Vermeulen et al. 2016:3). Thirdly, firms can gain higher market share, with recurrent information updating, accurate customer demand information, fast product design processes, reduced obsolete inventories and responsiveness to customer needs (Zhang \& Huo 2013:550).

\section{Process integration as an element of supply chain integration}

Process integration includes conventional systems, knowledge sharing, joint activity development and coordinated decision making between supply chain partners (Haq \& Boddu 2017:10; Leuschner et al. 2013:38). Process integration is the degree to which a firm streamlines, facilitates and automates supply chain processes with supply chain partners (Liu et al. 2016:15). Process integration poses multiple benefits to supply chain partners. Process integration strengthens the potential for SCI by creating a virtual supply chain network, allowing supply chain partners to capture, organise and share vital information (Xu, Huo \& Sun 2014:1190). Process integration also improves the overall firm performance by creating customer value, detecting demand changes, executing ideal responses and improving efficiency (Zhang \& Huo 2013:550). Through process integration firms can act as a single entity; therefore, supply chain partners gain benefits of reduced lead times, cost, risks, improved service, distribution and sales (Prajogo \& Olhager 2012:515). 


\section{Interpersonal relationships}

Interpersonal relationships are the relationships between individuals who are involved in supply chain activities (Venter, Farrington \& Sharp 2013:43). IPRs exist between individuals who happen to do business and are separate from their business relationships (Gligor \& Holcomb 2013:329). IPRs provide multiple benefits. With IPRs, individuals are more driven to work together to find results (Mocke, Niemann \& Kotzé 2016:8). IPRs also achieve higher levels of customer retention, customer referrals, partner trust and commitment whilst improving operational performance (Gligor \& Holcomb 2013:328). With mutual understanding in IPRs, less effort and time are required to resolve process conflict (Rood et al. 2018:4). Supply chain partners must not use IPRs as a means to an end; instead, benefits must be realised because of building and nurturing long-term IPRs and IORs (Gligor \& Holcomb 2013:343). Although multiple benefits exist because of IPRs, supply chain partners must consider the potential risks. IPRs are time-consuming and require commitments by supply chain parties. When IPRs fail, suppliers are at risk of losing buyers, resulting in a loss of revenue and waste of time (Mocke et al. 2016:8). Supply chain partners have the risk of information privacy and are subject to other's misbehaviours (Chung et al. 2016:72-79). These misbehaviours include supply chain partners who misuse the trust and act solely in their own interest (Villena \& Craighead 2017:493). Three IPR elements influence IORs in a supply chain setting, such as personal affection, personal credibility and personal communication (Barnes et al. 2015:4; Rood et al. 2018:3; Wang et al. 2018a:1173).

\section{Personal affection as an element of interpersonal relationships}

As an internal element of IPRs, personal affection refers to an individual's feelings, sentiments and likeability that affect closeness between individuals (Barnes et al. 2015:10; Wang et al. 2016:843). IPRs play an essential role in SCI as IPRs can lead to open, accurate and in-time information sharing (Wang et al. 2016:844). As part of personal affection, likeability influences an individual's confidence in predicting partner's future behaviour (Pulles \& Hartman 2017:57). Therefore, likability influences strategic collaborations and willingness to engage amongst supply chain partners (Pulles \& Hartman 2017:60).

\section{Personal credibility as an element of interpersonal relationships}

Personal credibility is the ability to gain the trust and confidence of others and to be viewed as credible or competent (Barnes et al. 2015:38; Rood et al. 2018:3). Personal credibility is based on the facts and data on previous achievements and performance (Wang et al. 2018b:832). Unlike personal affection, personal credibility is viewed objectively and not subjectively. Therefore, amongst the three elements of IPRs, personal credibility is the most likely to impact business transactions during the early stages (Wang et al. 2018a:1180). Personal credibility can also result in organisational collaborations as supply chain partners can build trust with personal credibility (Barnes et al. 2015:9; Wang et al. 2018a:1183).

\section{Personal communication as an element of interpersonal relationships}

Personal communication refers to the use of words, signs and language to facilitate the timely flow of information and to coordinate activities between individuals (Wieland \& Wallenburg 2013:302). Developing effective personal communication often improves IPRs, because it creates flexibility, harmony, responsiveness and cohesion (Rood et al. 2018:4; Wang et al. 2018b:832). Amongst the three elements of IPRs, personal communication is regarded as the only external attribute and is ranked as the most important to affect IORs (Wang et al. 2018a:1181, 2018b:832). Personal communication provides multiple benefits to supply chain partners. Personal communication enables individuals to create mutual understanding and closeness through information sharing (Gligor \& Autry 2012:25). Furthermore, personal communication achieves harmony in IPRs, as it develops feelings that agreed obligations and promises can be delivered (Barnes et al. 2015:11; Wang et al. 2018a:1174). Finally, personal communication facilitates the formation of IORs and SCI by clarifying plans, intentions and strategies of supply chain partners whilst resolving conflict and reducing risks (Wang et al. 2018a:1181). Therefore, communication and IPRs are critical to supply chain partners to achieve SCI. IPRs are an essential resource for supply chain partners, although IPRs must be incorporated into IORs to act as an enabler for SCI. It has also been argued that IORs cannot be built unless IPRs are built first (Gligor \& Holcomb 2013:329).

\section{Inter-organisational relationships}

Inter-organisational relationships can improve supply chain partner's responsiveness, efficiency, joint problem solving, conflict resolution and customer satisfaction (Jie, Parton \& Cox 2013:1005-1007; Vermeulen et al. 2016:4). IORs are long-term business relationships between supply chain partners who are working together towards mutual goals (Ebers 2015:621-625). With IORs, supply chain partners can cooperate in terms of process integration, information sharing, joint programs and strategic interface teams (Geng, Mansouri \& Aktas 2017; Lo et al. 2018:525). Although other elements such as justice, culture and leadership have been identified in literature to influence SCI, trust, commitment and power have been identified as the most important elements of IORs to enable SCI (Vermeulen et al. 2016:2; Wang et al. 2018a:1173; Zhang \& Huo 2013:545).

\section{Trust as an element of inter-organisational relationships}

Trust is a broadly and multi-faceted construct; however, trust is generally defined as follows (Lo et al. 2018:526; Shi \& Liao 2015:945):

Faith in the moral integrity of exchange partners, which is developed through business interactions and leads to inter- 
organisational bonds in terms of common goals, sentiments, and relationships in the face of uncertainty.

Trust also includes supply chain partners to rely on each other, because they have faith in each other not to act opportunistically but rather to be honest and benevolent (Wang et al. 2018a:1174; Zhang \& Huo 2013:545). Supply chain partners achieve trust by sharing common characteristics, being honest, sharing personal information and by establishing mutual rules in the relationship (Tsanos \& Zografos 2016:10). Well-established trust provides multiple benefits to supply chain partners as follows: Trust reduces risks and complexities because trust allows supply chain members to anticipate the behaviours of others (Chung et al. 2016:71; Rood et al. 2018:4). Trust also reduces vulnerability, uncertainty and opportunism attached to relationships. Therefore, supply chain partners can increase relationship quality, commitments and cooperation and can achieve collaboration between partners (Tsanos \& Zografos 2016:13; Zhang \& Huo 2013:545). Supply chain responsiveness increases as trust reduce transaction times and speed up the flow of funds and materials (Haq \& Boddu 2017:10).

\section{Relationship commitment as an element of inter- organisational relationships}

Relationship commitment is defined as the willingness and readiness to invest physical-, financial- or relationship-based resources in maintaining a relationship (Huo et al. 2015a:890; Zhao et al. 2008:370). In addition, firms must be willing to make sacrifices, showing their commitment to the relationships (Rood et al. 2018:4). Relationship commitment is instrumental or normative. An instrumental relationship commitment refers to one party accepting the influence of another with the hopes of receiving a favourable reaction in return. In contrast, normative relationship commitment is an ongoing, mutual relationship over a long period, based on sharing and mutual commitments (Huo et al. 2015:890; Zhao et al. 2008:371). These commitment efforts lead to both internal and external SCI, as commitment strengthens and stabilises relationships (Rood et al. 2018:4). If supply chain partners fear losing exclusive information and are fighting for scarce resources, commitments and trust may be lost (Vermeulen et al. 2016:4).

\section{Power as an element of inter-organisational relationships}

Power stems from the ownership of resources perceived as important by others (Wu, Chuang \& Hsu 2014:124). Power is the dependence between supply chain partners and the ability of one party to influence the behaviours and decisions of others (Wu et al. 2014:124). As a result of global mergers and acquisitions, buyers are growing in size and becoming fewer in numbers. Therefore, power is shifting from upstream suppliers to downstream buyers in the supply chain (Christopher 2016:17; Wang et al. 2016:846). Suppliers are also dependent on the purchases of buyers to ensure future business and to remain competitive in markets (Mocke et al. 2016:4). Previous studies found that IORs elements, such as trust, power and commitment, play crucial roles in achieving
SCI goals and competitive advantages (Lo et al. 2018; Wang et al. 2018a; Zhang \& Huo 2013).

\section{The role of interpersonal relationships during different stages of supply chain integration}

IPR elements such as personal affection, personal credibility and personal communication influence SCI elements of strategic alliances, information integration and process integration. However, IPRs rely on IORs to act as an intermediary to influence SCI (Wang et al. 2016:844). It has also been argued that IORs cannot be built unless IPRs are built first (Gligor \& Holcomb 2013). IPRs between boundary spanners play a fundamental role in IORs, as IORs are positively influenced by a harmonious relationship between individuals (Pulles \& Hartman 2017:56; Venter et al. 2013:43). IPRs between boundary spanners modify and shape the evolution of IORs. Therefore many alliances fail because firms fail to nurture and give attention to IPRs (Gligor \& Holcomb 2013:331; Pulles \& Hartman 2017:57). The three IPR elements are critical to IORs because the exchange of materials, financial exchange and exchange of resources between firms occur through human interaction (IPRs) (Barnes et al. 2015:10). Although all three elements of IPRs play a role in IORs, the influence of the elements differ throughout the SCI process (Wang et al. 2018a:1185). Figure 1 indicates the influences of personal affection, personal credibility and personal communication on IORs at different stages of SCI process and displays the influence of personal credibility and personal affection getting weakened over time whilst showing an increasing influence from personal communication on IORs throughout the SCI process.

As SCI matures from the formative stage to the operational stage, the influence of IPRs on IORs changes. Personal affection influences the initiation of IORs by increasing supply chain partner's willingness to collaborate (Pulles \& Hartman 2017:61; Wang et al. 2018a:1183). Therefore, personal affection is essential during the formative stages of SCI. However, the role of personal affection then becomes weaker in the operational stage of SCI as firms become interdependent over time (Wang et al. 2018a:1184). Personal credibility plays a significant role in IORs during the formative stage, but the influence becomes weaker over time. During the formative stage, boundary spanners look at an

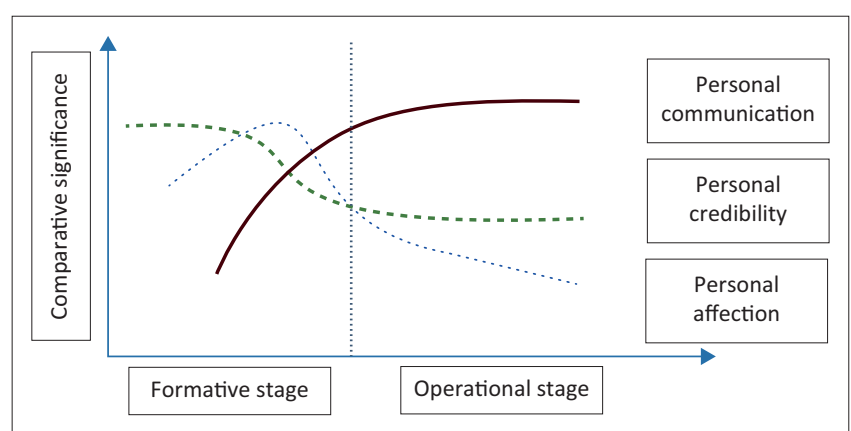

Source: Wang, B., Kang, Y., Childerhouse, P. \& Huo, B., 2018a, 'Interpersonal and interorganizational relationship drivers of supply chain integration', Industrial Management \& Data Systems 118(6), 1184. https://doi.org/10.1108/IMDS- 05-2017-0216

FIGURE 1: Personal affection, personal credibility and personal communication in supply chain integration process. 
individual's personal credibility before considering a potential partner for IORs (Wang et al. 2018a:1185). During the operational stage, personal credibility maintains some influence on IORs as it generates trust (Wang et al. 2018a:1184). Personal communication has limited influence at the formative stage as supply chain partners tend to communicate in less depth (Wang et al. 2018a:1184). However, the influence of personal communication on IORs tends to increase during the operational stages of SCI as it helps with information exchange and process coordination (Wang et al. 2018a:1185).

\section{Methodology}

The following sections explain the methodology applied in this study.

\section{Research design}

This study applied a generic qualitative research design to investigate the role of IPRs on IORs during both the formative and operational stages of SCI. A generic qualitative research design was used because the researchers possessed some preunderstanding of the specific phenomenon under investigation and wished to fully describe the topic from the perspective of the participants (Percy, Kostere \& Kostere 2015:78). Crosssectional primary data were gathered by conducting semistructured interviews with managers of 3PL firms in South Africa, which were used to create a deeper understanding of the experiences and perceptions of participants regarding the specific phenomenon (Myers 2013:5).

\section{Sampling}

The unit of analysis for this study was specific 3PLs that met the inclusion criteria. The unit of observation for this study was the individual participant employed by the 3PL organisations. This study expanded on the research by Wang et al. (2018a:1171-1186), by investigating the role of IPRs on IORs during both the formative and operational stages of SCI in a different context. This study was conducted in the South African 3PL service industry to see if the findings by Wang et al. (2018a:1171-1186) hold true in a different context. The researchers deliberately selected the most appropriate 3PL providers and participants to provide rich information. As such, this study made use of homogeneous sampling, a form of purposive sampling to deliberate select organisations and individuals based on clear pre-specified characteristics (Patton 2015:266-273).

Twelve participants from 12 firms took part in this study. One participant from each firm was interviewed. The following inclusion criteria at the firm level were used. Firstly, firms must have had operations in South Africa. Secondly, firms should have been established 3PL providers who perform and manage a range of logistics services as an external provider for their clients. Thirdly, firms must have been involved in SCI practices with supply chain partners. The following inclusion criteria at an individual level were
TABLE 1: Description of the participants' profiles.

\begin{tabular}{llcc}
\hline $\begin{array}{l}\text { Participant } \\
\text { ID }\end{array}$ & Job title & $\begin{array}{c}\text { Organisation } \\
\text { ID }\end{array}$ & $\begin{array}{c}\text { Interview } \\
\text { duration (min) }\end{array}$ \\
\hline P1 & Branch manager & O1 & 26 \\
P2 & Operations executive & O2 & 45 \\
P3 & Business development executive & O3 & 25 \\
P4 & Senior human resources manager & O4 & 28 \\
P5 & Business unit director & O5 & 20 \\
P6 & Managing director & O6 & 36 \\
P7 & National product manager & 07 & 25 \\
P8 & General manager for land distribution & 08 & 29 \\
P9 & Customer service manager & 09 & 13 \\
P10 & Trade lane and partner development & 010 & 24 \\
P11 & manager & & \\
P12 & Managing director & 011 & 16 \\
\hline
\end{tabular}

Average interview duration: $25 \mathrm{~min}$.

used. Participants should be the employees at the selected 3PL with a minimum of 2 years' experience in logistics to ensure that the individuals possess the needed experience to provide the necessary information. In addition, individuals must have worked as a middle or senior manager within the firm. Details of each participant can be found in Table 1 . The final sample size was based on the guidelines of Guest, Bunce and Johnson (2006:61), which state that 6-12 interviews are usually sufficient for the development of meaningful themes when sampling from a homogenous population.

\section{Data collection}

Researchers developed a comprehensive discussion guide from available literature. Semi-structured face-to-face interviews were used to gain an in-depth understanding of the specific topic (Rowley 2012). The semi-structured interviews took place at the offices of the participants. The discussion guide was pre-tested with a general manager within a 3PL firm. This participant was not included in the final sample as some changes were made to the discussion guide. Researchers asked participants to sign an informed consent form, gave assurance of confidentiality and anonymity and asked for permission to audio record participants.

\section{Data analysis}

This study used a thematic analysis approach to analyse the collected data. Thematic analysis is a way to systematically code, identify, organise and understand emerging themes within a data set (Braun \& Clarke 2013:57). Researchers made use of ATLAS.ti version 8 to guide the thematic analysis approach. ATLAS.ti is a sophisticated software program used to systematically analyse complex phenomena hidden in unstructured qualitative data. An initial analysis was performed by listening to the audio-recordings whilst reading the interview transcripts to become acquainted with the data and to generate preliminary inductive codes (Creswell 2012:243). A list of codes was then compiled. Later, similar or redundant codes were combined or deleted as needed. These codes were then grouped into different theme sets. Codes and themes were constantly revised, amended 
when necessary and finally aligned with the research questions (Braun \& Clarke 2013:4).

\section{Trustworthiness}

A four-criterion framework was employed to ensure the trustworthiness of this study. The criteria included credibility, dependability, confirmability and transferability (Polit \& Beck 2012:584). Credibility refers to the level of accuracy between the findings of this study and the truth of a phenomenon (Shenton 2004:64). Credibility was obtained through space triangulation, which involves the researcher collecting data from multiple organisations (Polit \& Beck 2012:590). Dependability implies that if work is to be replicated in the same context, using the same methods and with similar participants, the findings should be consistent (Lietz \& Zayas 2010:197). Dependability was ensured through an external audit. The external audit included an experienced supply chain management academic scrutinise the processes of data collection, data analysis and the results of the research study (Polit \& Beck 2012:594). Confirmability implies that data collected will reflect a participant's true opinion and will not be influenced by researcher bias (Milne \& Oberle 2005:415-416). To ensure confirmability, interviews were audio-recorded and transcribed in their entirety. Transferability refers to how well a study's findings can be transferred and applied to other settings and context (Polit \& Beck 2012:585). Transferability was ensured by providing a detailed methodology and inclusion criteria for firms and participants (Elo et al. 2014:6).

\section{Ethical consideration}

Ethical approval to conduct the study was obtained from the Faculty of Economic and Management Sciences Research

\begin{tabular}{|c|c|c|c|}
\hline Themes & $\begin{array}{l}\text { Theme 1: Interpersonal } \\
\text { relationship's influence } \\
\text { on inter-organisational } \\
\text { relationships }\end{array}$ & $\begin{array}{l}\text { Theme 2: Interpersonal } \\
\text { relationship's role on } \\
\text { inter-organisational } \\
\text { relationships during } \\
\text { formative stage }\end{array}$ & $\begin{array}{l}\text { Theme 3: } \\
\text { Interpersonal } \\
\text { relationship's } \\
\text { maturity in supply } \\
\text { chain integration }\end{array}$ \\
\hline $\begin{array}{l}\text { Sub- } \\
\text { themes }\end{array}$ & $\begin{array}{l}\text { - Positive influences } \\
\text { - Ease of doing } \\
\text { business } \\
\text { - Enhanced trust } \\
\text { - Enhanced business } \\
\text { accommodation } \\
\text { - Improved customer } \\
\text { retention } \\
\text { - Negative influences } \\
\text { - Unethical practices } \\
\text { - Crossing the line } \\
\text { - Bias judgement } \\
\text { - Personal issues } \\
\text { affecting the } \\
\text { business }\end{array}$ & $\begin{array}{l}\text { - Personal affection } \\
\text { - Jeopardise business } \\
\text { - Creates buy-in } \\
\text { - Business factors take } \\
\text { priority } \\
\text { - Improved service } \\
\text { delivery } \\
\text { - Personal credibility } \\
\text { - Enhanced trust } \\
\text { - Ease of doing business } \\
\text { - Gaining new business } \\
\text { - Personal communication } \\
\text { - Improved } \\
\text { - Enderstanding } \\
\text { - Enhanced comfort } \\
\text { - Enhe of doing business } \\
\text { - Enhanced trust }\end{array}$ & $\begin{array}{l}\text { - Personal affection } \\
\text { maturity } \\
\text { - Personal credibility } \\
\text { maturity } \\
\text { - Personal } \\
\text { communication } \\
\text { maturity }\end{array}$ \\
\hline
\end{tabular}

Ethics Committee at the University of Pretoria (Ethical Clearance Number: 14192561/2019, 11 Aug 2019). Before the start of each interview, the researcher verbally reminded participants that each interview was voluntary and they could withdraw or refuse to answer any question at any time, that both their identity and their organisation's identity would be kept anonymous, and that all information would be treated confidentially. These conditions were also provided in an informed consent form. Each participant was asked to read and sign the informed consent form before the commencement of the interview.

\section{Findings}

The findings of each of this study's research questions are reported in this section. As illustrated in Table 2, this study identified three main themes and various sub-themes related to the study's research questions. The three themes and subthemes mentioned in Table 2 are discussed in the following sections.

\section{Theme 1: Interpersonal relationship's influence on inter-organisational relationships}

The research question 1 relates to how IPRs amongst boundary spanners influence the IORs. The following subsections describe the positive and negative influences of IPRs on IORs.

\section{Positive influences}

Table 3 illustrates the positive influences of IPRs on IORs as identified by 12 participants.

Seven participants identified that IPRs allowed supply chain partners to conduct business more easily, as IPRs created an atmosphere and understanding that enabled individuals to interact more comfortably with each other, as illustrated by the following quotation:

'II is] to try and match up an atmosphere that allows it to be relatively easier for me to interact with you on a business level because of the nature of the personal touch we have.' (P2, male, operations executive)

In this study, six participants stated that they were more willing to engage in business when they trusted a person based on their IPRs, as demonstrated by the following quotation:

'That might assist with the business relationship because the personal relationship might stem on a trust, I would rather do business with a person that I know, opposed to someone that I don't know.' (P4, male, senior human resources manager)

TABLE 3: Positive influences of interpersonal relationships on inter-organisational relationships.

\begin{tabular}{|c|c|c|c|c|c|c|c|c|c|c|c|c|}
\hline Positive influence & P1 & $\mathbf{P 2}$ & P3 & P4 & P5 & P6 & P7 & P8 & P9 & P10 & P11 & P12 \\
\hline Ease of doing business & $\bullet$ & - & • & $\bullet$ & - & $\bullet$ & - & - & - & - & - & - \\
\hline Enhanced trust & - & - & $\bullet$ & $\bullet$ & $\bullet$ & $\bullet$ & - & - & $\bullet$ & $\bullet$ & & - \\
\hline Enhanced business accommodation & $\bullet$ & $\bullet$ & - & - & $\bullet$ & $\bullet$ & $\bullet$ & - & - & - & $\bullet$ & - \\
\hline Improved customer retention & - & - & - & - & - & - & - & - & $\bullet$ & - & - & • \\
\hline
\end{tabular}


Furthermore, six participants mentioned that IPRs influence the IORs positively because of enhanced accommodation. Through IPRs, supply chain partners were willing to go the extra mile to accommodate each other as seen in the following quotation:

'I have worked with the person for many years, and with that relationship, I can pick up the phone, and that person would do anything for us.' (P7, female, national product manager)

IPRs also improved customer retention. Two participants stated that they were able to strengthen future relationships and retain customers for life, as illustrated by the following quotation:

'You're going to have the customer or the client for life.'

(P9, male, customer service manager)

\section{Negative influences}

Table 4 illustrates the negative influences of IPRs on IORs as identified by the 12 participants.

Interpersonal relationships could lead to unethical practices in business. Activities such as bribery, corruption and favouritism were viewed as unethical practices by participants and could occur as a result of IPRs. Therefore, firms implemented policies, standards, corporate governance and procedures to limit the influence of IPRs on IORs. Seven participants believed that these practices could negatively influence the IORs as seen by the following quotation:

'We do have personal relationships with people, but we keep it to a business level so that it is not too personal, in case it might be seen as favouritism towards a supplier.' (P7, female, national product manager)

Five participants stated that IPRs could negatively influence the IORs because people started crossing the line between a personal and a business relationship. With IPRs, individuals began to cross the line of ethical compliance standards implemented by their firm. As a result, unethical practices could occur, which is evident in the following quotation:

'Many firms in SA or world does have ethical and compliance standards. So, as long as we don't cross those borders, things are good. Sometimes firms miss construed business and personal relationships that is when corruption takes place.' (P4, male, senior human resources manager)
Interpersonal relationships create bias judgements as IPRs influence their decision making. As a result of the IPR, judgement is bias as members might give lower prices, better service and favourable contracts to others as mentioned by two participants. This is illustrated by the following quotation:

'Your personal relationship with your supplier, it clouds judgment, it clouds service and offer clouds the pricing.' (P11, female, managing director)

When things did go wrong in their IPRs, it harmed the IORs. When IPR conflicts occur, people might start to take steps towards moving away from the business relationship. The quotation below illustrates how personal issues between individuals affect business as stated by two participants:

'If you have a personal relationship with an individual and something negative occurs, it could also affect that business relationship.' ( $\mathrm{P} 8$, male, general manager for land distribution)

These findings confirmed the work of Wang et al. (2018a:1178) as IPRs influence IORs in a South African 3PL context. This study also corroborates the existing literature by Mocke et al. (2016:8), who found that ease of doing business and enhanced trust are benefits of IPRs. Furthermore, the results also verify the findings by Rood et al. (2018:11) who found that IPR could also have negative effects through biased judgment where members are lenient towards each other.

\section{Theme 2: the role of interpersonal relationships on inter-organisational relationships during formative stage of supply chain integration}

The second research question of this study aims to understand the role of IPRs on IORs during the formative stage of SCI. This section discusses the influence of the three elements of IPRs on IORs during the formative stage of SCI.

\section{Personal affection}

The view that personal affection has an influence on IORs during the formative stages of SCI was split equally. Six participants stated that personal affection positively influences IOR, as their likeability towards an individual could create buy-in and improve willingness to engage in business. The six remaining participants believed the opposite. These participants believed personal affection to negatively influence IORs and that business factors should take priority. Table 5 shows the influence of personal affection on the IORs during the formative stages of SCI.

TABLE 4: Negative influences of interpersonal relationships on inter-organisational relationships.

\begin{tabular}{|c|c|c|c|c|c|c|c|c|c|c|c|c|}
\hline Negative influence & P1 & P2 & P3 & P4 & P5 & P6 & P7 & P8 & P9 & P10 & P11 & P12 \\
\hline Unethical practices & $\bullet$ & $\bullet$ & - & $\bullet$ & $\bullet$ & - & $\bullet$ & $\bullet$ & - & $\bullet$ & - & - \\
\hline Crossing the line & - & - & $\bullet$ & $\bullet$ & - & - & $\bullet$ & - & - & $\bullet$ & $\bullet$ & - \\
\hline Bias judgement & - & - & - & - & $\bullet$ & - & - & - & - & - & $\bullet$ & - \\
\hline Personal issues affect business & - & - & - & - & - & - & - & $\bullet$ & - & - & $\bullet$ & - \\
\hline
\end{tabular}

TABLE 5: Formative personal affection influences

\begin{tabular}{|c|c|c|c|c|c|c|c|c|c|c|c|c|}
\hline Formative personal affection influence & P1 & $\mathbf{P 2}$ & P3 & P4 & P5 & P6 & P7 & P8 & P9 & P10 & P11 & P12 \\
\hline Jeopardise business & $\bullet$ & - & $\bullet$ & $\bullet$ & $\bullet$ & - & - & • & $\bullet$ & $\bullet$ & - & - \\
\hline Creates buy-in & - & $\bullet$ & $\bullet$ & - & - & $\bullet$ & $\bullet$ & - & - & - & $\bullet$ & - \\
\hline Business factors takes priority & - & - & - & - & $\bullet$ & $\bullet$ & - & $\bullet$ & $\bullet$ & $\bullet$ & - & - \\
\hline Improved service delivery & - & - & - & - & • & - & • & - & - & - & - & - \\
\hline
\end{tabular}


Table 5 shows that IPRs can have both positive and negative influences on IORs during the formative stage of SCI.

Seven participants mentioned that personal affection could negatively affect the IORs and jeopardise business. Participants noted that personal affection clouded judgement, created bias and could cause the business to miss opportunities as seen by the following quotation:

'You tend to overlook it, or you take action at a very slower pace than what you intend to do ... so then the business suffers the outcomes.' (P8, male, general manager for land distribution)

On the other hand, five participants stated that personal affection influenced the IORs positively because of their likeability towards a person created buy-in. Buy-in relates to the willingness of firms to engage in SCI activities faster, as illustrated by the following quotation:

'I think if you have got somebody that's more receptive to you as a person and also to your company you tend to support them more.' (P11, female, managing director)

Although participants stated that personal affection created buy-in, five participants indicated that business factors such as service delivery, processes, products and price should take priority over personal feelings, as illustrated by the following quotation:

'IIf the] price is competitive and they tick all the boxes with compliance, then it is not about how you feel about them, it's about the service they can provide.' (P10, male trade lane and partner development)

The following quote shows that personal affection influenced the IORs positively by gaining improved service delivery:

'A benefit could be service delivery...you might prioritise my business and my needs compared to someone you don't have a good relationship with.' (P5, male, business unit director)

\section{Personal credibility}

All but one participant stated that personal credibility positively influenced the IORs during the formative stages of SCI. Table 6 illustrates the various influences of personal credibility on IORs during the formative stages of SCI.
Nine participants suggested that personal credibility influenced IORs because of trust. Therefore, enhanced trust is the most dominant influence of personal credibility on IORs during the formative stages of SCI. Participants trusted supply chain partners when partners were honest, had their best interests at heart and could rely on them to get things done. The following quotation supports this finding:

'If a person has no ethics or a lack of it, you won't deal with that firm because need to trust that person. You need to know they have your best interest at heart and that they will look after your business as their own.' (P7, female, national product manager)

Six participants stated that personal credibility influences the IORs because they would be able to conduct business more easily when an individual was credible as illustrated by the following quotation:

'If credibility is there and your word is your word ... you find that the connection between the two companies becomes easy.' (P2, male, operations executive)

Four participants were more likely to start new business ventures when supply chain partners were seen as credible. Therefore, personal credibility contributed to supply chain partners gaining new business, as seen in the following quotation:

'If a person or firm has personal credibility, then the likelihood of you ... starting business with them is very good.' (P6, male, managing director)

\section{Personal communication}

All but one participant stated that personal communication positively influenced IORs during the formative stages of SCI. Table 7 shows the influence personal communication has on the IORs during the formative stages of SCI.

Nine participants mentioned that through personal communication, they were able to enhance understanding in IORs. Through personal communication, individuals could understand each other's problems, thinking, needs and expectations. The following quotation supports this finding:

'You get to understand people better, you get an in-depth view of the partnership and what they see as important.' (P8, male, general manager for land distribution)

TABLE 6: Formative personal credibility influences.

\begin{tabular}{|c|c|c|c|c|c|c|c|c|c|c|c|c|}
\hline Formative personal credibility influences & P1 & $\mathbf{P 2}$ & P3 & P4 & P5 & P6 & P7 & P8 & P9 & P10 & P11 & P12 \\
\hline Enhanced trust & - & $\bullet$ & - & $\bullet$ & $\bullet$ & - & $\bullet$ & $\bullet$ & $\bullet$ & $\bullet$ & $\bullet$ & $\bullet$ \\
\hline Ease of doing business & $\bullet$ & $\bullet$ & $\bullet$ & - & $\bullet$ & - & - & $\bullet$ & - & - & - & $\bullet$ \\
\hline Gaining new business & - & - & _- & - & - & - & • & - & _- & - & - & - \\
\hline
\end{tabular}

TABLE 7: Formative personal communication influence.

\begin{tabular}{|c|c|c|c|c|c|c|c|c|c|c|c|c|}
\hline Formative personal communication influence & P1 & P2 & P3 & P4 & P5 & P6 & P7 & P8 & P9 & P10 & P11 & P12 \\
\hline Improved understanding & $\bullet$ & $\bullet$ & $\bullet$ & - & $\bullet$ & $\bullet$ & $\bullet$ & $\bullet$ & $\bullet$ & $\bullet$ & - & - \\
\hline Enhanced comfort & $\bullet$ & $\bullet$ & - & - & - & - & - & $\bullet$ & - & $\bullet$ & - & - \\
\hline Ease of doing business & - & - & - & - & $\bullet$ & - & $\bullet$ & - & $\bullet$ & $\bullet$ & - & $\bullet$ \\
\hline Enhanced trust & $\bullet$ & - & - & $\bullet$ & - & $\bullet$ & - & - & - & - & - & - \\
\hline
\end{tabular}


Five participants suggested that personal communication created comfort in the work environment. Through personal communication, partners got to know each other better and were more comfortable when interacting, as illustrated by the following quotation:

'Early on in integration, where there is stronger communication, it creates comfort and confidence.' ( $\mathrm{P} 2$, male, operation executive)

Personal communication influenced the IORs as five participants stated that they are able to conduct business more easily. Through personal communication, individuals are able to improve negotiations and ensure smooth business operations because there are no hidden agendas and surprises. This finding is illustrated by the following quotation:

'It makes the whole process smooth and easier when people can communicate.' (P5, male, business unit director)

Three participants are of the opinion that personal communication enhances trust. Personal communication enables transparency in the IOR; through transparency, individuals build trust as they can see the intentions of others. The following quotation shows that personal communication influences the IORs by enhancing trust:

'Trust will be built on performance according to expectations that has been clearly communicated.' (P6, male, managing director)

These findings confirm the findings by Wang et al. (2018a:1181), who stated that personal affection and credibility play a significant role in influencing IORs. The findings in this study also confirm the findings by Wang et al. (2018a:1181), who indicated that personal communication influences IOR. However, the negative influence of personal affection on IOR is of concern as it could jeopardise business. Personal affection should not take priority over business factors such as service delivery, processes, products and price.

\section{Theme 3: Interpersonal relationship maturity in supply chain integration}

The third research question of this study relates to the influence of IPR elements on IORs changes from the formative to operational stages of SCI. This theme reports on how personal affection, personal credibility and personal communication matured from the formative to operational stages of SCI.

\section{Personal affection maturity}

Only one participant mentioned that personal affection had a more prominent role during the formative stages of SCI. Three participants reported that the role was equally important, and seven participants said that personal affection played a more critical role in IORs during the operational stages of SCI. These seven participants felt personal affection to have a more important role during the operational stages of SCI, as it helped to maintain a comfortable and understanding environment, as seen in the following quotation:
'I think it grows over time, first impressions last but some people, you need to get to know them first before you understand them.' (P7, female, national product manager)

These findings contradict the findings by Wang et al. (2018a:1181), who stated that the role of personal affection tends to weaken and become more limited over time.

\section{Personal credibility maturity}

Participant views on the maturity of personal credibility throughout the SCI process were split. Three participants indicated that personal credibility played a more important role in IORs during the formative stages of SCI. The following quotation illustrates this view:

'It's more important in the beginning, to get it quicker so that you get a build quicker result.' (P9, male, customer service manager)

Four participants indicated that personal credibility played a more critical role in IORs during the operational stages of SCI as shown by the following quotation:

'It is more important later on; initially, you scrutinise everything they say, you only build relationships and credibility over time.' (P6, male, managing director)

Five participants stated that personal credibility played an equally important role in IORs throughout the SCI process. Participants noted that personal credibility should always be a part of business and should never fall away, as supported by the following quotation:

'As you kick off, you need to end. It's important throughout from start to finish.' (P12, male, regional manager)

These findings contradict the findings by Wang et al. (2018a:1181), who stated that the role of personal credibility tends to decline over time. However, results also agree with Wang et al. (2018a:1181), in the sense that personal credibility may still have some influence because of personal trust.

\section{Personal communication maturity}

Five participants indicated that personal communication played a more critical role in IORs during the formative stages of SCI. Participants believed personal communication allowed supply chain partners to lay down foundations early on as shown by the following quotation:

'In the early stages I believe it is more important as that is when your setup everything like processes and supply chain. So, if you get that wrong then the end-stage will be a total mess.' (P5, male, business unit director)

Only two participants mentioned that personal communication played an equally important role in IORs throughout the SCI process, as illustrated by the following quotation:

'The personal communication, integration alignment and reporting remain critical.' (P2, male, operation executive)

Four participants suggested that personal communication played a more critical role in IORs during the operational 
stages of SCI. As shown in the quotation below, participants believed that personal communication matured over time and influenced IORs more during the operational stages of SCI:

'It is a function of maturity that as the relationship matures, so does the level of conversation in the relationship.' (P3, male, business development executive)

These findings do not support the findings of Wang et al. (2018a:1181), who stated that the role of personal communication on IORs is likely to increase throughout the SCI process.

\section{Conclusion}

The following section provides a summary of the main research findings, key managerial implications, limitations of the study and recommendations for future research.

\section{Summary of findings and theoretical implications}

The purpose of this generic qualitative study was to replicate the previous research by Wang et al. (2018a:1170-1186) in a South African service context. More specifically, the first research question set out to investigate the role of IPRs on IORs during different stages of SCI in the 3PL industry in South Africa. This study found that IPRs influence the occurrence of IORs both positively and negatively. IPRs have a positive influence on IORs between 3PLs and their clients through ease of doing business, enhanced trust, enhanced business accommodation and improved customer retention. The results of this study confirm the findings by Wang et al. (2018a:1170-1186), who stated that IPRs lead to the development of formal IORs. However, the findings also revealed that negative influences such as unethical practices, crossing the line, clouding of judgement and personal issues influencing the business should not be ignored.

The second research question explored the role of IPR elements on IORs during the formative stages of SCI. The first element of IPRs, namely, personal affection had both positive and negative influences on IORs during the formative stages of SCI. This study found personal affection to influence the IORs negatively and to jeopardise the IORs as personal affection clouds judgement, create bias and cause businesses to miss opportunities. In addition, the research found that participants believed that business factors such as price, quality and service should take priority over personal feelings. Although some negative influences exist, this study also found personal affection to influence the IORs positively as it creates buy-in and can improve service delivery. These findings confirm the work by Wang et al. (2018a:1170-1186) who stated that personal affection plays a significant role in influencing IORs. However, the negative influences should be addressed during the formative stages of SCI. The second element of IPRs, namely personal credibility, was found to strongly influence the IORs through enhanced trust, ease of doing business and individuals being able to gain new business opportunities. These findings confirm the findings of Wang et al. (2018a:1170-1186) who stated that personal credibility is strongly related to trust and influences the IORs during the formative stages of SCI. The third element of IPRs, namely, personal communication was also found to influence IORs as it results in enhanced understanding. Personal communication results in improved understanding as individuals are able to understand supply chain partner's needs, expectations, problems and thinking. Personal communication also influences IORs during the formative stages of SCI through enhanced comfort, trust and ease of doing business. Therefore, thisstudy confirms thefindingsofWanget al.(2018a:1170-1186), as this study found personal communication to have a strong influence on IORs during the formative stages of SCI.

The third research question aimed to understand how the role of IPR elements on IORs changes during the operational stages of SCI. This study found the first element, namely personal affection, to have a more prominent role during the operational stages of SCI. These findings contradict the findings by Wang et al. (2018a:1170-1186), who stated that the role of personal affection tends to become weaker during the operational stages of SCI. These findings could be contradictory because of diverse ethnicities, cultures, languages and backgrounds of the South African workforce (Cannon et al. 2010:506). Furthermore, this study found that the role of personal credibility is of equal importance during both stages of SCI. The findings in this study contradict Wang et al. (2018a:1170-1186), who stated that the role of personal credibility tends to decline over time. However, Wang et al. (2018a:1184) also noted that personal credibility may still play a role during the operational stages of SCI, because of personal trust. The findings of this study confirm this statement as personal credibility plays a significant role in IORs throughout the SCI process because of enhanced trust. Personal credibility remains important throughout the SCI process. Personal credibility is important in the formative stages to get a trustworthy partner who is able to satisfy the needs of the business and to deliver fast results. During the operational stages, personal credibility is important as a partner needs to be able to keep the trust of his partners by continuously delivering results.

This study found the role of personal communication to have mixed results. The findings do not yield exact results about the maturity of personal communication, as 5 of 12 participants stated that the role was more important during the formative stages of SCI and four participants noted the role was more important during the operational stages of SCI. These findings, therefore, contradict the previous findings of Wang et al. (2018a:1170-1186) who stated that the role of personal communication in IORs is likely to increase throughout the SCI process. These findings may be contradicting as a result of the 11 national languages in South Africa and English being the second language of many people. Language plays an important role as supply chain partners must be able to speak and understand each other to align for common goals (Anderson et al. 2018:44). Therefore, findings may be contradictory as some participants felt that communication 
played a critical role in setting up SCI practices, whereas others believed that communication played a crucial role in operating and maintaining SCI practices.

\section{Managerial implications and recommendations}

This study assists supply chain managers by increasing their awareness of the influence of IPRs on IORs during SCI practices. Therefore, this study could encourage managers to engage in IPRs with supply chain partners to gain benefits from IPRs such as ease of doing business, enhanced trust, business accommodation and customer retention. This study also creates awareness that supply chain managers must be mindful of the possible negative influence of IPRs, as personal relationships have embedded risks. Practically, firms should encourage supply chain managers to invest and commit towards the formulation of strong IPRs. This investment includes efforts to understand and work closely with individuals of supply chain partner firms.

In addition, this study enables supply chain managers to gain an understanding of the influence of IPR elements such as personal affection, credibility and communication on IORs during the formative stages of SCI. Firms should evaluate employees based on their affection, credibility and communication skills and selectively partner them with specific supply chain partners. As a result, managers can more effectively leverage their IPR elements of personal affection, credibility and communication to improve their IORs during the formative stages of SCI. Finally, this study allows managers to gain an understanding of how the role of IPRs in IORs changes during the operational stages of SCI. It is recommended that managers ensure they have high levels of personal affection during the operational stages of SCI whilst maintaining high levels of credibility and communication throughout the SCI process. Account managers should receive training on how to deal with supply chain partner individuals who demonstrate personalities that are different from their own and how to manage these individuals' expectations during different stages of SCI.

\section{Limitations and directions for future research}

This study has a few limitations, which suggest further research. Despite analysing several 3PL providers, this study fails to address the role of IPRs in IORs during different stages of SCI from the perspective of other supply chain partners, such as suppliers and customers. It would be beneficial for future research studies to consider the perspectives of all supply chain partners when exploring the role of IPRs in IORs during different stages of SCI. Furthermore, participants were not asked to declare the size of their firms. Large firms are required to have formal corporate governance and strict processes and policies in place. These measures could limit the formation of personal relationships in large firms and influence results. Future research could be conducted to identify the influence of firm size to help further understand the role of IPRs in IORs during the SCI process. Finally, as a result of semi-structured interviews, participants may have withheld valuable information to protect themselves and maintain good face during data collection. Therefore, researchers could consider using alternative data collection methods such as survey methods to test the strength of the relationships between the constructs.

\section{Acknowledgements Competing interests}

The authors have declared that no competing interests exist.

\section{Authors' contributions}

This article is based on the MPhil dissertation of T.V.S. who was the main researcher. W.N. and A.M. acted as the supervisors with the conceptualisation, literature review, research instrument and development of this manuscript.

\section{Funding information}

This research received no specific grant from any funding agency in the public, commercial or not-for-profit sectors.

\section{Data availability statement}

Data are stored according to institutional policy.

\section{Disclaimer}

The views and opinions expressed in this article are those of the authors and do not necessarily reflect the official policy or position of any affiliated agency of the authors.

\section{References}

Aitken, J., Childerhouse, P., Deakins, E. \& Towill, D., 2016, 'A comparative study of manufacturing and service sector supply chain integration via the uncertainty circle model', International Journal of Logistics Management 27(1), 188-205.

Anderson, E.G., Chandrasekaran, A., Davis-Blake, A. \& Parker, G.G., 2018, 'Managing distributed product development projects: Integration strategies for time-zone and language barriers', Information Systems Research 29(1), 42-69. https://doi org/10.1287/isre.2017.0733

Barnes, B.R., Leonidou, L.C., Siu, N.Y. \& Leonidou, C.N., 2015, 'Interpersonal factors as drivers of quality and performance in Western-Hong Kong interorganizational business relationships', Journal of International Marketing 23(1), 23-49. https:// doi.org/10.1509/jim.14.0008

Boon-itt, S., Wong, C.Y. \& Wong, C.W., 2017, 'Service supply chain management process capabilities: Measurement development', International Journal of Production Economics 193(1), 1-11. https://doi.org/10.1016/j.ijpe.2017.06.024

Braun, V. \& Clarke, V., 2013, Successful qualitative research: A practical guide for beginners, Sage, London.

Cannon, J.P., Doney, P.M., Mullen, M.R. \& Petersen, K.J., 2010, 'Building long-term orientation in buyer-supplier relationships: The moderating role of culture', Journal of Operations Management 28(6), 506-521. https://doi.org/10.1016/j. jom.2010.02.002

Cao, Z., Huo, B., Li, Y. \& Zhao, X., 2015, 'The impact of organizational culture on supply chain integration: A contingency and configuration approach', Supply Chain Management: An International Journal 20(1), 24-41. https://doi.org/10.1108/ SCM-11-2013-0426

Christopher, M., 2016, Logistics and supply chain management, 5th edn., Pearson Education, New York, NY.

Chung, H.F., Wang, C.L., Huang, P.-H. \& Yang, Z., 2016, 'Organizational capabilities and business performance: When and how does the dark side of managerial ties matter?', Industrial Marketing Management 55(1), 70-82. https://doi. org/10.1016/j.indmarman.2016.02.014

Creswell, J.W., 2012, Educational research: Planning, conducting, and evaluating quantitative and qualitative research, 4th edn., Pearson, Boston, MA

Danese, P., Romano, P. \& Formentini, M., 2013, 'The impact of supply chain integration on responsiveness: The moderating effect of using an international supplier network', Transportation Research Part E: Logistics and Transportation 49(1), 125-140. https://doi.org/10.1016/j.tre.2012.08.002 
Ebers, M., 2015, Interorganizational relationships and networks, Elsevier, Oxford.

Elo, S., Kääriäinen, M., Kanste, O., Pölkki, T., Utriainen, K. \& Kyngäs, H., 2014 'Qualitative content analysis: A focus on trustworthiness', SAGE Open 4(1), 1-10. https://doi.org/10.1177/2158244014522633

Geng, R., Mansouri, S.A. \& Aktas, E., 2017, 'The relationship between green supply chain management and performance: A meta-analysis of empirical evidences in Asian emerging economies', International Journal of Production Economics 183(Part A), 245-258. https://doi.org/10.1016/j.ijpe.2016.10.008

Gligor, D.M. \& Autry, C.W., 2012, 'The role of personal relationships in facilitating supply chain communications: A qualitative study', Journal of Supply Chain Management 48(1), 24-43. https://doi.org/10.1111/j.1745-493X.2011.03240.x

Gligor, D.M. \& Holcomb, M., 2013, 'The role of personal relationships in supply chains: An exploration of buyers and suppliers of logistics services', International Journal of Logistics Management 24(3), 328-355. https://doi.org/10.1108/IJLM 07-2012-0067

Goldsby, T.J. \& Autry, C.W., 2011, 'Toward greater validation of supply chain management theory and concepts: The roles of research replication and metaanalysis', Journal of Business Logistics 32(4), 324-331. https://doi.org/10.1111/ j.0000-0000.2011.01028.x

Guest, G., Bunce, A. \& Johnson, L., 2006, 'How many interviews are enough? An experiment with data saturation and variability', Field Methods 18(1), 59-82. https://doi.org/10.1177/1525822X05279903

Gunasekaran, A., Irani, Z., Choy, K.-L., Filippi, L. \& Papadopoulos, T., 2015, 'Performance measures and metrics in outsourcing decisions: A review for research and measures and metrics in outsourcing decisions: A review for research and https://doi.org/10.1016/j.ijpe.2014.12.021

Haq, A.N. \& Boddu, V., 2017, 'Analysis of enablers for the implementation of leagile supply chain management using an integrated fuzzy QFD approach', Journal of Intelligent Manufacturing 28(1), 1-12. https://doi.org/10.1007/s10845-014Intellig

Huo, B., 2012, 'The impact of supply chain integration on company performance: An organizational capability perspective', Supply Chain Management: An International Journal 17(6), 596-610. https://doi.org/10.1108/13598541211269210

Huo, B., Liu, C., Kang, M. \& Zhao, X., 2015a, 'The impact of dependence and relationship commitment on logistics outsourcing: Empirical evidence from greater China', International Journal of Physical Distribution \& Logistics Management 45(9/10), 887-912. https://doi.org/10.1108/IJPDLM-04-2015-0109

Huo, B., Ye, Y. \& Zhao, X., 2015b, 'The impacts of trust and contracts on opportunism in the 3PL industry: The moderating role of demand uncertainty', Internationa Journal of Production Economics 170(Part A), 160-170. https://doi.org/10.1016/j. ijpe.2015.09.018

Išoraitè, M., 2014, 'Importance of strategic alliances in company's activity', Intellectual Economics 1(5), 39-46.

Jie, F., Parton, K.A. \& Cox, R.J., 2013, 'Linking supply chain practices to competitive advantage: An example from Australian agribusiness', British Food Journal 115(7), 1003-1024. https://doi.org/10.1108/BFJ-10-2010-0181

Leuschner, R., Carter, C.R., Goldsby, T.J. \& Rogers, Z.S., 2014, 'Third-party logistics: A meta-analytic review and investigation of its impact on performance', Journal of Supply Chain Management 50(1), 21-43. https://doi.org/10.1111/jscm.12046

Leuschner, R., Rogers, D.S. \& Charvet, F.F., 2013, 'A meta-analysis of supply chain integration and firm performance', Journal of Supply Chain Management 49(2), 34-57. https://doi.org/10.1111/jscm.12013

Lietz, C. \& Zayas, L.E., 2010, 'Evaluating qualitative research for social work practitioners', Advances in Social Work 11(2), 188-202. https://doi.org/10.18060/589

Liu, H., Wei, S., Ke, W., Wei, K.K. \& Hua, Z., 2016, 'The configuration between supply chain integration and information technology competency: A resource orchestration perspective', Journal of Operations Management 44(1), 13-29. https://doi.org/10.1016/j.jom.2016.03.009

Lo, S.M., Zhang, S., Wang, Z. \& Zhao, X., 2018, 'The impact of relationship quality and supplier development on green supply chain integration: A mediation and moderation analysis', Journal of Cleaner Production 202(1), 524-535. https://doi. org/10.1016/j.jclepro.2018.08.175

Luke, R. \& Waugh, B., 2011, 'Logistics outsourcing by manufacturers in South Africa', Journal of Transport and Supply Chain Management 5(1), 337-360. https://doi. org/10.4102/jtscm.v5i1.81

Marchet, G., Melacini, M., Perotti, S. \& Sassi, C., 2018, 'Types of logistics outsourcing and related impact on the 3PL buying process: Empirical evidence', Internationa Journal of Logistics Systems and Management 30(2), 139-161. https://doi. org/10.1504/IJLSM.2018.091959

Milne, J. \& Oberle, K., 2005, 'Enhancing rigor in qualitative description', Journal of Wound, Ostomy and Continence Nursing 32(6), 413-420. https://doi org/10.1097/00152192-200511000-00014

Mocke, K., Niemann, W. \& Kotzé, T., 2016, 'The role of personal relationships between buyers and suppliers of third-party logistics services: A South African perspective', Acta Commercii 16(1), 1-13. https://doi.org/10.4102/ac.v16i1.367

Myers, M.D., 2013, Qualitative research in business and management, 2nd edn., Sage, Croydon.

Niemann, W., Meyer, A., Kotzé, T. \& Odendaal, J., 2018, 'The role of third-party logistics providers as orchestrators in emerging markets', in Proceedings of the 12 th International Business Conference, Mauritius, September 2018, pp. 174312th International Business Conference, Mauritius, September 2018, pp. 1743-
1746 , viewed 30 April 2019, from https://www.researchgate.net/profile/Wesley 1746, viewed 30 April 2019, from https://www.researchgate.net/profile/Wesley Niemann/publication/330513194_THE_ROLE_OF_THIRD_PARTY_LOGISTICS
PROVIDERS AS ORCHESTRATORS IN EMERGING MARKETS/links/5c4577 $\bar{b}$ PROVIDERS_AS_ORCHESTRATORS_IN_EMERGING_MARKETS/links/5c4577b
992851c22a384a282/THE-ROLE-OF-THIRD-PARTY-LOGISTICS-PROVIDERS-AS992851c22a384a282/THE-ROLE-OF-THIRD-PART
ORCHESTRATORS-IN-EMERGING-MARKETS.pdf.
Patton, M.Q., 2015, Qualitative research \& evaluation methods: Integrating theory and practice, 4th edn., Sage, Upper Saddle River, NJ.

Percy, W.H., Kostere, K. \& Kostere, S., 2015, 'Generic qualitative research in psychology', The Qualitative Report 20(2), 76-85.

Polit, D.F. \& Beck, C.T., 2012, Nursing research: Generating and assessing evidence for nursing practice, 9th edn., Lippincott Williams \& Wilkins, Philadelphia, PA.

Porter, M.G., 2019, 'Supply chain integration: Does organizational culture matter?', Operations and Supply Chain Management-An International Journal 12(1), 49-59.

Prajogo, D. \& Olhager, J., 2012, 'Supply chain integration and performance: The effects of long-term relationships, information technology and sharing, and logistics integration', International Journal of Production Economics 135(1), 514-522. https://doi.org/10.1016/j.ijpe.2011.09.001

Pulles, N.J. \& Hartman, P., 2017, 'Likeability and its effect on outcomes of interpersonal interaction', Industrial Marketing Management 66(1), 56-63. https://doi. org/10.1016/j.indmarman.2017.06.008

Rood, C., Van den Berg, D., Niemann, W. \& Meyer, A., 2018, 'The role of personal relationships in supply chain disruptions: Perspectives from buyers and suppliers of logistics services', Acta Commercii 18(1), 1-15.

Rowley, J., 2012, 'Conducting research interviews', Management Research Review 35(3/4), 260-271.

Shaiq, M., Alwi, S.K., Shaikh, S. \& Zaman, Z., 2020, 'Quality management as driver of vertical integration in service Chain: A study of 3rd party logistics industry', Operations and Supply Chain Management: An International Journal 13(3), 244-255. https://doi.org/10.31387/oscm0420266

Shenton, A.K., 2004, 'Strategies for ensuring trustworthiness in qualitative research projects', Education for Information 22(2), 63-75.

Shi, X. \& Liao, Z., 2015, 'Inter-firm dependence, inter-firm trust, and operational performance: The mediating effect of e-business integration', Information \& Management 52(8), 943-950. https://doi.org/10.1016/j.im.2015.06.010

Stevens, G.C. \& Johnson, M., 2016, 'Integrating the supply chain... 25 years on', International Journal of Physical Distribution \& Logistics Management 46(1), 19-42. https://doi.org/10.1108/IJPDLM-07-2015-0175

Tsanos, C.S. \& Zografos, K.G., 2016, 'The effects of behavioural supply chain relationship antecedents on integration and performance', Supply Chain Management: An International Journal 21(6), 678-693. https://doi.org/10.1108/ SCM-06-2016-0211

Venter, E., Farrington, S. \& Sharp, G., 2013, 'The influence of relational-based issues on job satisfaction and organisational commitment in family businesses: The views of non-family employees', Management Dynamics 22(4), 38-57.

Vermeulen, Y., Niemann, W. \& Kotzé, T., 2016, 'Supply chain integration: A qualitative exploration of perspectives from plastic manufacturers in Gauteng', Journal of Transport and Supply Chain Management 10(1), 1-13. http://doi.org/10.4102/ jtscm.v10i1.223

Villena, V.H. \& Craighead, C.W., 2017, 'On the same page? How asymmetric buyersupplier relationships affect opportunism and performance', Production and Operations Management 26(3), 491-508. https://doi.org/10.1111/poms.12648

Wang, B., Childerhouse, P., Kang, Y., Huo, B. \& Mathrani, S., 2016, 'Enablers of supply chain integration: Interpersonal and interorganizational relationship perspectives' Industrial Management \& Data Systems 116(4), 838-855. https://doi.org/10.1108/ IMDS-09-2015-0403

Wang, B., Kang, Y., Childerhouse, P. \& Huo, B., 2018a, 'Interpersonal and interorganizational relationship drivers of supply chain integration', Industria Management \& Data Systems 118(6), 1170-1191. https://doi.org/10.1108/IMDS 05-2017-0216

Wang, B., Kang, Y., Childerhouse, P. \& Huo, B., 2018b, 'Service supply chain integration: The role of interpersonal relationships', Industrial Management \& Data System 118(4), 828-849. https://doi.org/10.1108/IMDS-02-2017-0062

Wieland, A. \& Wallenburg, C., 2013, 'The influence of relational competencies on supply chain resilience: A relational view', International Journal of Physical Distribution \& Logistics Management 43(4), 300-320. https://doi.org/10.1108/ IJPDLM-08-2012-0243

Wu, I.-L., Chuang, C.-H. \& Hsu, C.-H., 2014, 'Information sharing and collaborative behaviors in enabling supply chain performance: A social exchange perspective' International Journal of Production Economics 148(1), 122-132. https://doi. org/10.1016/j.ijpe.2013.09.016

Xu, D., Huo, B. \& Sun, L., 2014, 'Relationships between intra-organizational resources, supply chain integration and business performance', Industrial Management \& Data Systems 114(8), 1186-1206.

Yunus, E.N. \& Tadisina, S.K., 2016, 'Drivers of supply chain integration and the role of organizational culture: Empirical evidence from Indonesia', Business Process Management Journal 22(1), 89-115. https://doi.org/10.1108/BPMJ-12-20140127

Zhang, H. \& Okoroafo, S.C., 2015, 'Third-party logistics (3PL) and supply chain performance in the Chinese market: A conceptual framework', Engineering Management Research 4(1), 38-48. https://doi.org/10.5539/emr.v4n1p38

Zhang, M. \& Huo, B., 2013, 'The impact of dependence and trust on supply chain integration', International Journal of Physical Distribution \& Logistics Management 43(7), 544-563. https://doi.org/10.1108/IJPDLM-10-2011-0171

Zhao, X., Huo, B., Flynn, B.B. \& Yeung, J.H.Y., 2008, 'The impact of power and relationship commitment on the integration between manufacturers and customers in a supply chain', Journal of Operations Management 26(3), 368-388. https://doi.org/10.1016/j.jom.2007.08.002 